Article

\title{
Promoting a World Heritage Site through Social Media: Suwon City's Facebook Promotion Strategy on Hwaseong Fortress (in South Korea)
}

\author{
Sung-Won Yoon ${ }^{1}$ and Sae Won Chung ${ }^{2, *}$ \\ 1 Division of Business Administration, The University of Suwon, Hwaseong-si 18323, Korea; \\ syoon@suwon.ac.kr \\ 2 Graduate School of International Studies, Korea University, Seoul 02841, Korea \\ * Correspondence: swchung37@korea.ac.kr
}

Received: 8 May 2018; Accepted: 19 June 2018; Published: 27 June 2018

\begin{abstract}
This paper examines how Hwaseong Fortress, a UNESCO-designated World Heritage Site in South Korea, has been promoted by the city of Suwon by social media. Suwon is the capital of Gyeonggi-do, South Korea's most populous province, which surrounds Seoul and embraces abundant historical heritages, such as the Hwaseong Fortress. To celebrating the creation of the fortress and its historical values, the city has hosted various cultural events every year, including the year 2016, when the city celebrated '2016 Visit Year Suwon Hwaseong.' As for promotion, the city actively utilises social media platforms, such as Facebook, to raise public attention to the event. This paper attempts to examine how effectively and actively the city promoted the events through social media from 2015 to 2017. Facebook was a particular focus because of its popularity among the Korean public. By comparatively exploring network features, subordinate features and semantic features captured by Node XL for the targeted years, the authors examine any specific changes over time in the city's promotion patterns. Furthermore, based on the key findings, some suggestions are provided for further development of the promotion strategy.
\end{abstract}

Keywords: Suwon Hwaseong fortress; promotion strategy; city branding; UNESCO World Heritage; social media; Facebook; 2016 Visit Year Suwon Hwaseong

\section{Introduction}

In principle, a cultural city implies a space where the residents lead cultural lives. It further describes the space in a creative economy where new economic value is created. The latter notion is associated with the former government's top agenda, named the 'creative economy'. In other words, cultural cities create economic value by exploiting or discovering underestimated cultural assets. In addition, this economic value should benefit the citizens. The current government is paying special attention to 'culture' as a means to creating the new value needed to realise creative economy.

In South Korea, the notion of a cultural city was highlighted in the 1990s. After the municipal system was introduced in 1995, increasingly fierce competition between different local governments led to a nationwide boom of 'cultural cities' [1] (p. 2). The idea of creating the image of Suwon as a cultural city emerged in this context as well.

This paper addresses Suwon city's promotion of world heritage on social media. The municipal government has actively promoted the Hwaseong festivals and events through various social media platforms. Due to the advent of smart technology, social media has become the most effective advertising platform for the Korean public. In 2017, 90.3\% of the South Korean population were using the internet [2], $94.1 \%$ of Korean households were using a smartphone to connect to the internet 
and $68.2 \%$ of internet users were accessing social media platforms [3]. Social media is indeed one of the most useful tools for city promotion. The contents disseminated by the town can be stored in a wide range of different media types, such as print (newspapers, magazines and books), photos (Facebook, Twitter or Instagram) and videos (YouTube), and the city can share such information with everyone [4]. To determine the impact of a city's promotion strategy, the exploration of social networks embedded in social media is a meaningful and useful approach. This study focuses on Facebook as a medium of analysis due to its high usage in South Korea. Figure 1 below supports our claim.

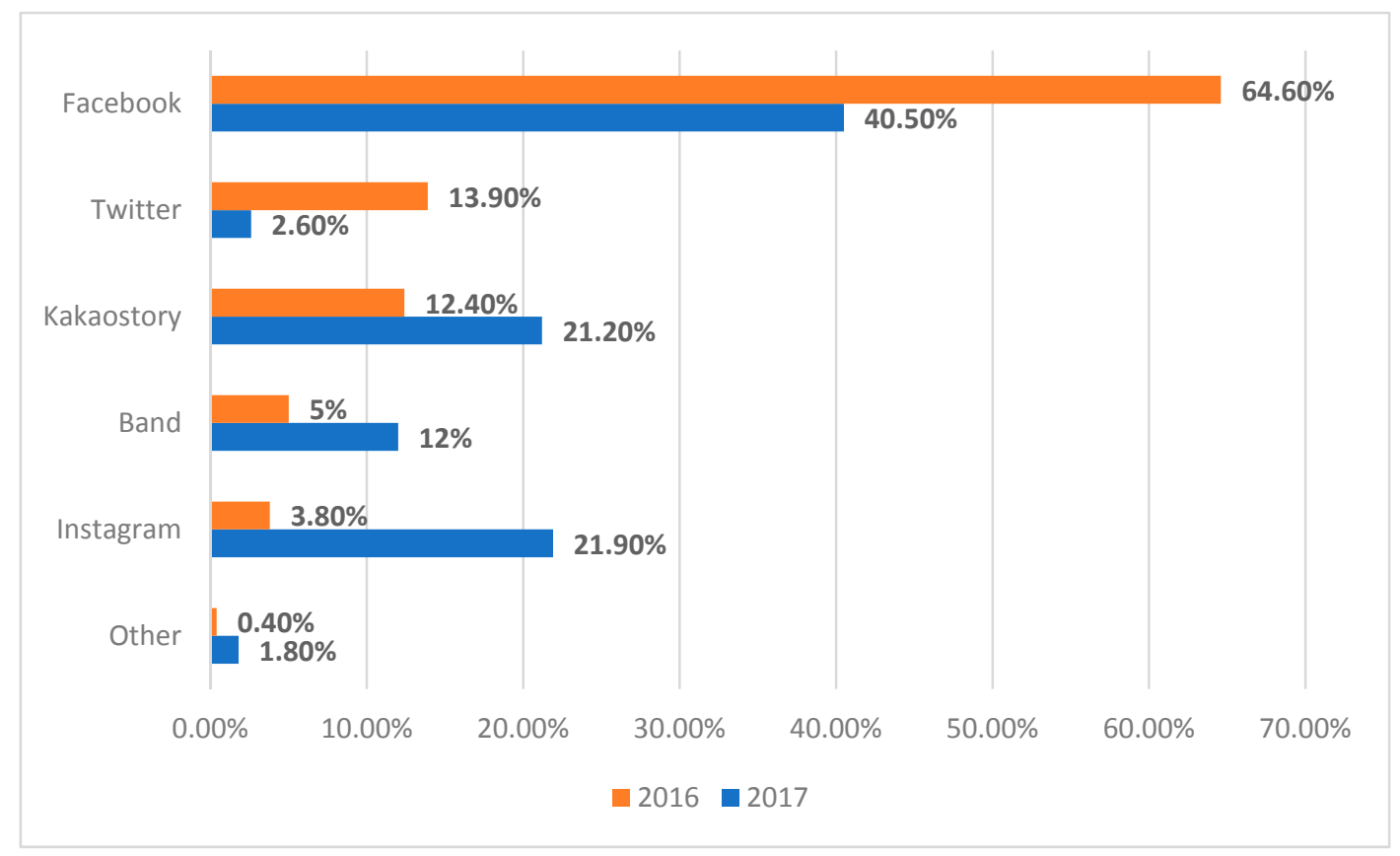

Figure 1. Primary social media platforms used by social media users in South Korea in 2016 \& 2017 (\% of respondents) [5].

In exploring Suwon city's branding strategy through the lens of social network analysis-Facebook, in particular-the following three questions were addressed:

Q1. What were the features of the postings on the Suwon Hwaseong Facebook fan page over the period from 2015 to 2017?

Q2. How did the Suwon Hwaseong Facebook fan page form its social networks over the period from 2015 to 2017 ?

Q3. What were the features of the structure of the semantic networks of the Suwon Hwaseong Facebook fan page over the period from 2015 to 2017?

Based on these research questions, this paper drew out six hypotheses. They are as follows:

Hypothesis 1 (H1). '2016 Visit Year Suwon Hwaseong' will have a higher number of postings than 2015 and 2017.

Hypothesis 2 (H2). Regarding the number of monthly postings, the peak will be in the month of the Suwon Hwaseong Festival.

Hypothesis 3 (H3). The Suwon Hwaseong Facebook fan page administrators will have maintained the closest relationships with followers in 2016.

Hypothesis 4 (H4). The year 2016 will mark the best year in terms of quality of network connection. 
Hypothesis 5 (H5). The network formed in 2016 will have the highest information diffusion efficiency.

Hypothesis 6 (H6). Semantically, the Suwon Hwaseong Facebook Facebook fan page will have distributed the most diverse range of themes in their postings during the year 2016.

\section{Site Description}

\subsection{Suwon as a 'Cultural' City}

The city of Suwon is the capital of Gyeonggi-do which surrounds Seoul in South Korea. It has typically been known as the city of industry, because the headquarters and R\&D centre of Samsung Electronics are based there (Figure 2). Although the city has abundant historical heritage, such as the Hwaseong Fortress, its cultural value has previously been underestimated. However, the Hwaseong Fortress was designated as UNESCO World Heritage in 1997 (Figure 3) [6]. The fortress was designed by Jeong Yak-yong, a leader of the Silhak movement. Inspired by the use of science and industry, as was emphasised by Silhak, Jeong used bricks as the main building material for the fortress. He also invented pulleys and cranes to be used for the construction process. The circumference of the fortress is $5744 \mathrm{~m}$, and its area is as much as 130 ha. The construction was once interrupted by a spell of dry weather, but the fortress was completed in 2.5 years under the leadership of King Jeongjo (r. 1776-1800) [7].

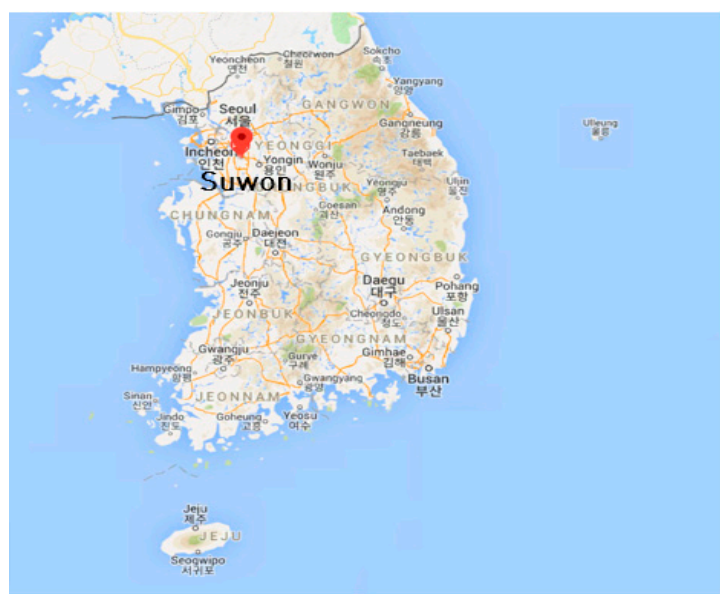

(a)

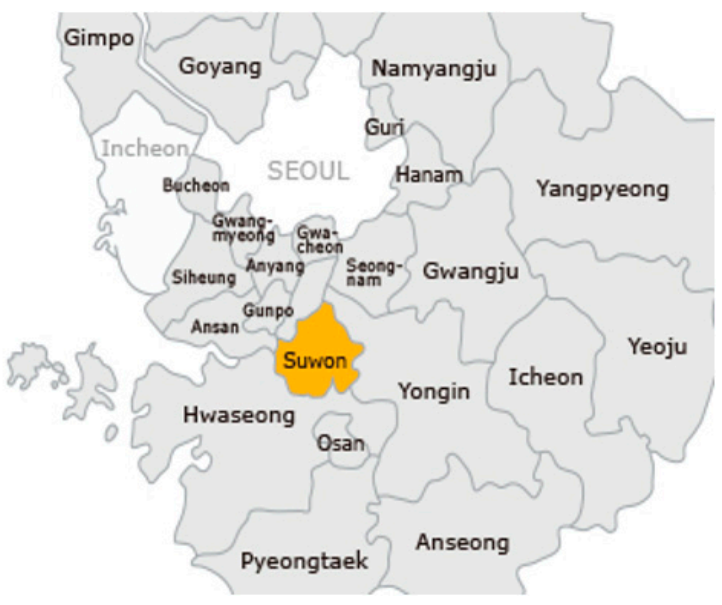

(b)

Figure 2. Maps of Suwon: (a) Suwon in South Korea [8], (b) Suwon in Gyeonggi-do [9].

Until the end of the 1800s, the fortress had maintained its original condition. However, after the 1900s, the fortress was no longer preserved safely. During the Japanese colonisation period, the fortress was destroyed. The Korean War in 1950 put Suwon at the centre of the battlefield [10]. Accordingly, the fortress was bombarded, and only a few structures were left. In the 1970s, the Korean government launched the implementation of fortress restoration. During the restoration effort in 1975, the ten volumes of Hwaseong Seongyeokuigwe (or Uigwe, which means 'Records of Hwaseong Fortress Construction') proved invaluable [11]. This restored fortress was enlisted as a UNESCO Memory of the World in 2007. Such an unprecedented case of UNESCO designation provided a catalyst to the local government and the citizens to reconsider the historical significance of the city. The current form of Hwaseong Fortress is presented in Figure 3. 


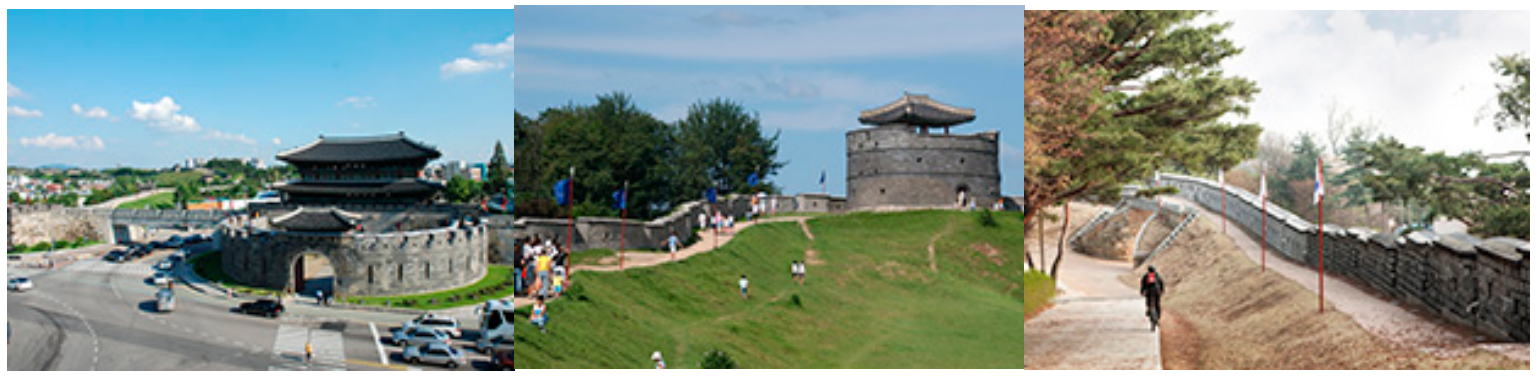

(a)

(b)

(c)

Figure 3. Images of Hwaseong Fortress: (a) Janganmun [12], (b) Dongbuk Gongsimdon [13], (c) Hwaseong Fortress Wall [14].

The underestimated cultural assets were newly exploited to generate economic value, and the local government is making efforts to rebrand the image of Suwon as a city of culture. From the 2000s, in particular, Suwon city aimed to identify itself as 'a city of history and culture'. The objective of the 2030 Suwon City Development Plan was to create a 'City of Historical Culture and High-Tech Industry.' The detailed strategies were to create a city brand and identity and to establish a historical city that people want to stay in. The city planned to implement several projects to create a historical and cultural city by engaging residents [15]. The most crucial issue concerned developing cultural contents on the Hwaseong fortress and the founder, King Jeongjo of Joseon Dynasty. Accordingly, some artistic performances were created. "Hwaseong International Theatre Festival" takes place every August. A musical, "Dream in Hwaseong", was created under the theme of King Jeongjo's filial piety to his father. Also, the fortress introduced martial arts performances and change of guards for daily events to visitors. "Hwaseong Cultural Festival," the most representative event of this kind, is held every October [16]. Its highlights include 'monarch procession', in which the pageants of King Jeongjo and Lady Hyegyeong, his mother, march through the fortress with hundreds of courtiers (Figure 4). The year 2016 was 'Visit Year Suwon Hwaseong', and the city promoted this cultural heritage and their events more than ever.

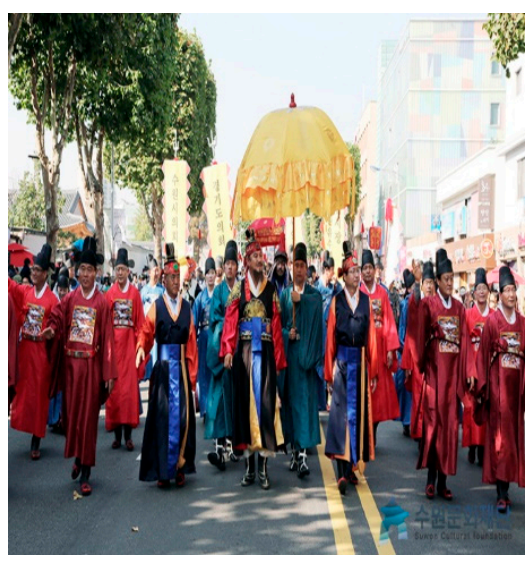

(a)

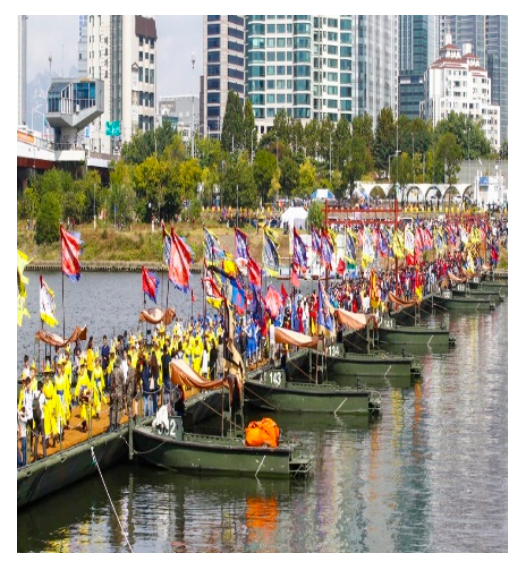

(b)

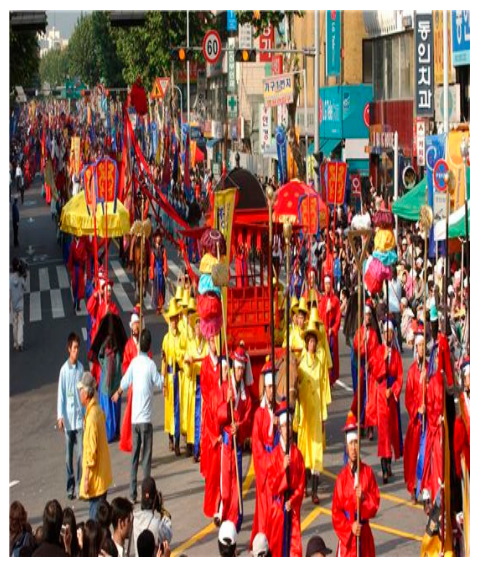

(c)

Figure 4. Monarch processions: (a) 2015 [17], (b) 2016 [18], (c) 2017 [19].

\subsection{Existing Studies on Suwon Hwaseong}

Research on Suwon Hwaseong has been continuously conducted in a diverse range of academic fields. The themes of previous empirical studies can be summarised into several branches. First, researchers have covered the historical meaning and architectural excellence of Suwon Hwaseong [20,21]. Moreover, Shim evaluated it as a successful case of urban regeneration because 
Suwon Hwaseong has been completely restored after it was once severely destroyed during the Japanese colonial rules and the Korean War [22,23]. Second, another group of researchers considered Suwon Hwaseong to be a case of the revitalisation of the regional economy and urban regeneration. This theme drew a significant amount of academic attention from a multitude of academic scholars other than those interested in the historical meaning of Suwon Hwaseong. In contrast to the significance and historical meaning of Suwon Hwaseong, the surrounding area of Suwon Hwaseong has been falling behind compared with other neighbouring areas due to the lack of developmental restrictions for the preservation and promotion of Suwon Hwaseong. Against this backdrop, there has been some concern about the significance of developing Suwon Hwaseong cultural contents to attract tourists and revitalise regional economies [24-27]. Furthermore, at the level of city branding, the necessity of developing travel contents and regional infrastructure has been continuously emphasized [28]. Also, stakeholders have discussed the matter of how to improve the cultural contents of Suwon Hwaseong in more detail [28]. Other than this group of researchers, there have been different types of research conducted regarding the effective preservation of Suwon Hwaseong $[15,29,30]$ and the effectiveness of mobile cultural travel service provision about Suwon Hwaseong regarding technical aspects [31,32].

Meanwhile, the promotion strategies of Suwon Hwaseong need further research because of their current scarcity. Recently, Choi attempted to evaluate the Suwon Hwaseong Festival and explore points of improvement for the programme [33]. Although in Korean society, social media has generally been utilised as a promotion tool for cultural heritage and cultural events, there has been no research on the social media approach in this regard. Thus, this paper would like to fill the current research gap by dealing with Suwon Hwaseong Festival's social media promotion strategies.

\section{Theoretical Framework}

Kavaratzis and Ashworth argued that there is no single accepted definition of branding [34] (p. 509). The scholars generally agreed that "the branding is more than an identifying name given to a product." To tackle place branding, it would be sensible to replace "a product" with "a place" [34] (p. 510). They subsequently suggested three major components of the brand. The first component is 'brand identity' which means how the owners want the brand to be perceived. The second component is 'brand positioning' which means the part of the value proposition communicated to a target group that demonstrates competitive advantage. The last component is 'brand image' which refers to how the brand is perceived. Against this backdrop, the brand image is a significant component of the investigation. Kavaratzis contended that "brand image is constructed through three distinct types of communication: primary, secondary and tertiary" [34] (p. 64). 'Primary communication' covers not only the architecture, urban design, infrastructure, museum and other place offerings but also the residents' or stakeholders' behaviours towards the city [35]. 'Secondary communication' is a kind of the promotion in the traditional marketing mix which utilises formal and intended communication methods, like advertising, public relations, graphic design, logos and slogans. 'Tertiary communication' is understood as a form of communication that is largely beyond the control of place marketers, because it consists of word-of-mouth reinforced by the media and a wide variety of city users like visitors or residents [36]. Based on our understanding, the investigation of social media platforms can be helpful for exploring place branding because such platforms show all of the abovementioned types of communication. Cleave et al. perceive social media to be an important element in the process of place promotion [37]. They applied Kavaratzis' model of brand communication to explore the social media place promotion framework. Their framework is provided in Figure 5. 


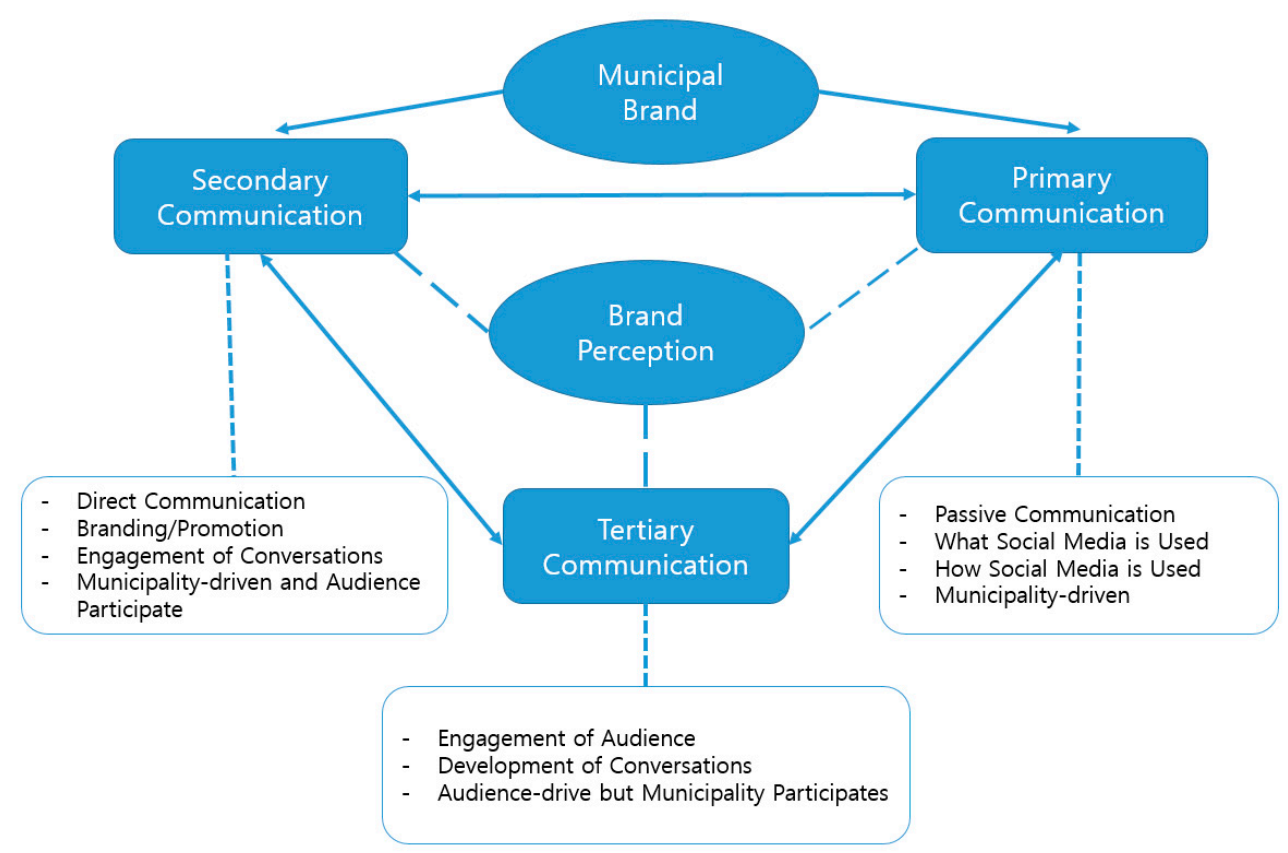

Figure 5. Social media place promotion framework [35] (p. 1016).

Cleave et al. found that social media platforms have been employed in the case of city branding [37]. However, they pointed out that the three major platforms-Facebook, Twitter and YouTube-are employable for further place brand development. It is because they can promote a brand by using diverse modes of contents, such as texts, photographs and videos.

Social media is a well-adapted and influential tool for city branding because it has an impact on place branding campaigns in two different aspects- 'communication' and 'co-creation' [37]. In terms of the communication aspect, social media presents opportunities for the secondary and tertiary communication processes. When the campaign engages in conversation with the target audience, the conversation will be developed into the engagement of audiences [38]. In terms of the co-creation aspect, the mass of people who visit the place and the place creators build the place brand together [39]. In this regard, the place brand consists of interactions between place, service, strategic communication activities and involves various stakeholders [38].

Empirical research studies about the relationship between social media and place branding have emerged over the last decade. Szondi revealed that the followers of the Facebook page of Budapest have played a significant role in creating a geographic and virtual community [40]. Wardrop covered the case of city branding in Edinburgh, and he found that Twitter and Facebook play significant roles in DEMA (Destination Edinburgh Marketing Alliance)'s reputation management [41]. Kim and Kim found out that YouTube contributed significantly to Seoul city branding because of its viral marketing campaign based on YouTube [42]. Björner investigated how Chengdu employed online city branding in its international positioning [43]. He pointed out that social media is an essential element for online city branding. In his case, Chengdu used its Facebook page to promote its city branding by posting a picture of Panda. Sevin attempted to evaluate the Define-Measure-Visualise (DMV) place-branding framework by analysing social and semantic networks from Twitter posts about Boston and New York City [44].

The existing literature on the relationship between city branding and social media is dominated by a focus on exploring social media's impact on city branding strategies. However, a close examination of the networks of social media remains under-researched. Against this backdrop, this paper attempts to explore the structures, the relationship patterns and the impacts of Suwon Hwaseong Festival's Facebook fan page post networks. 


\section{Materials and Methods}

The data for this paper were collected from three years, from 2015 to 2017. The year 2016 was the pivotal year for Suwon because of '2016 Visit Year Suwon Hwaseong'. The medium of social media used in this study was Facebook due to its popularity among the Korean public (Figure 6). There are a series of computer-aid analytic softwares, such as NetMiner, Pajek, Python, R and UCINET. This paper employed NodeXL which was developed by the Social Media Research Foundation. The strength of NodeXL is that it is easy-to-use, highly interactive with Microsoft Excel and allows efficient visualisation of network data.

The object of analysis was the Facebook fan page of the Suwon Hwaseong Festival. This paper focuses on the Facebook post network. The first step of social network analysis is finding out information about the Suwon Hwaseong official Facebook fan page.

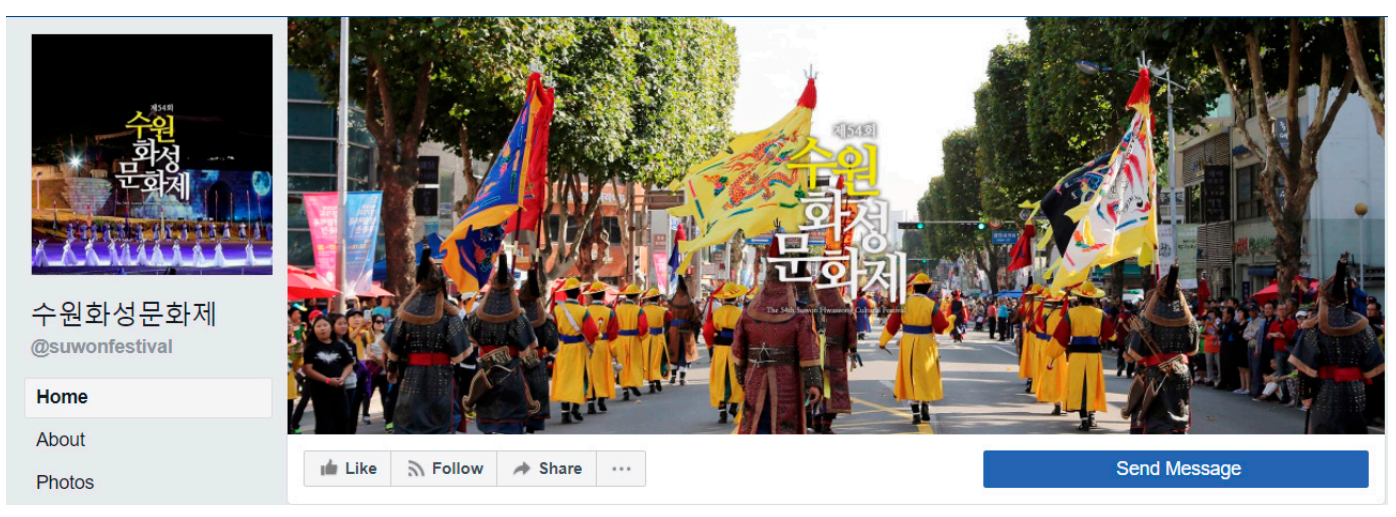

Figure 6. Facebook fan page for the Suwon Hwaseong Festival.

As shown in Figure 7, the ID of Suwon Hwaseong's Facebook Fan Page is @suwonfestival. After opening the NodeXL interface, the coder entered the ID into the blank of "import from Facebook Fan Page Network". After entering the ID into the blank, the ID automatically changed into code numbers. To extract the Facebook post network, the coder marked "post" under the vertices section. To determine the relationships between the edges, the coder marked "comment and post" and "reply and comment". To compare the results on a yearly basis, the coder set the download period separately by each year. For 2016, for instance, the coder set 1 January 2016 as the starting date and 31 December 2016 as the final date of the data set.

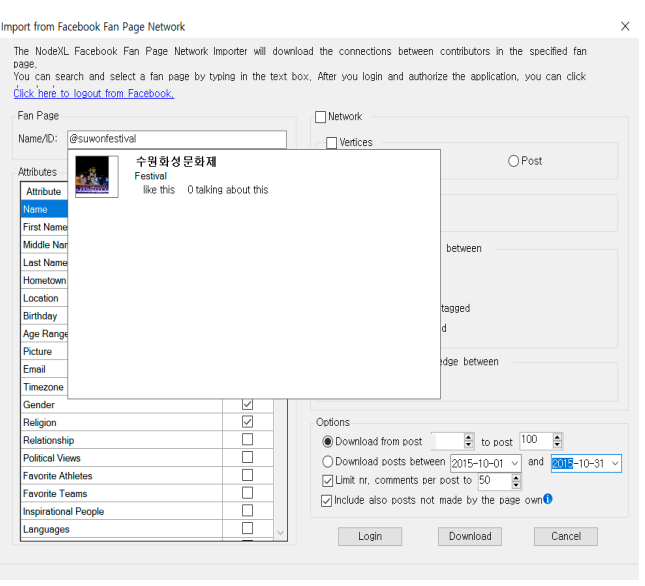

(a)

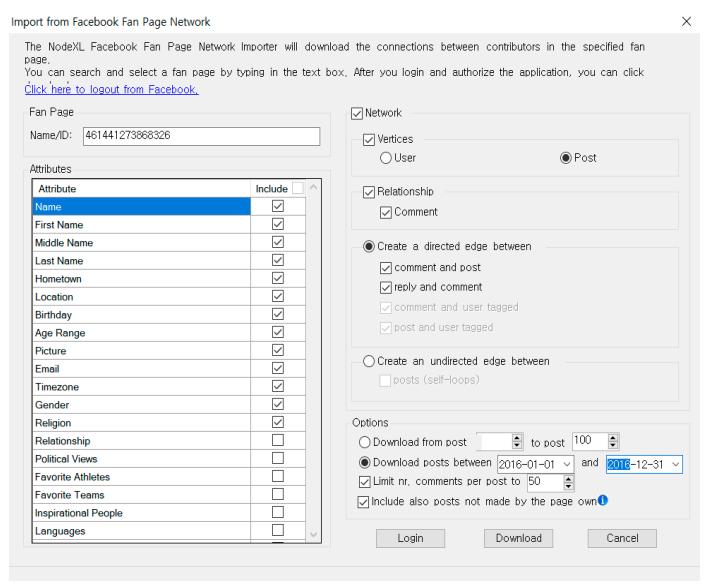

(b)

Figure 7. NodeXL Import from the Facebook fan page network (a) before inserting ID and (b) after inserting ID. 
Network graph metrics are useful for describing an entire network or characterising subgroups or specific actors within a single network [45]. There are two main groups of metrics in network graph: Aggregate Network Metrics and Vertex-Specific Metrics. Aggregate Network Metrics are useful for conducting systematical comparisons among communities and are helpful for analysts to find out which communities are highly or sparsely connected [45]. Through tracking the chronological development of aggregate network metrics, analysts can discover the effectiveness of interventions on the network as a whole [45]. Density, the first type of Aggregate Network Metrics, is the proportion of direct ties among the total number of relationships in a network. A different kind of Aggregate Network Metrics, the Geodesic Distance, indicates the maximum distance between the two most distant vertices. A shorter Geodesic Distance refers to closeness among the members of a network. As for the Vertex-Specific Metrics, the Degree Centrality covers the total number of links to a vertex, and within the degree centrality, there are two subordinate degrees: In-Degree and Out-Degree. The In-Degree indicates the specific individuals in the network who have drawn attention from other members of the network, which is calculated by the number of links connected to a node. The Out-Degree shows a specific node's outward actions with other nodes in the network, which is calculated by the number of links from a node to other vertices.

The Betweenness Centrality reveals who has the more control over the network. The Closeness Centrality suggests how fast was the information in the network diffused, and the Eigenvector Centrality shows who the most popular member of the network was. A summary of Aggregate Network Metrics and Vertex-Specific Metrics is provided in Table 1.

Table 1. Main concepts of social network analysis [45].

\begin{tabular}{|c|c|c|}
\hline Classification & Type & Description \\
\hline \multirow{2}{*}{$\begin{array}{l}\text { Aggregate Network } \\
\text { Metrics }\end{array}$} & Density & $\begin{array}{l}\text { The number of relationships observed to be present in } \\
\text { a network, divided by the total number of possible } \\
\text { relationships that could be present. }\end{array}$ \\
\hline & Geodesic Distance & $\begin{array}{l}\text { The distance of the shortest path between two people. } \\
\text { The Average Geodesic Distance gives a sense of how } \\
\text { close community members are from one another. }\end{array}$ \\
\hline \multirow{6}{*}{ Vertex-Specific Metrics } & Degree Centrality & $\begin{array}{l}\text { Gives the total number of links to a vertex, but does } \\
\text { not indicate link quality. }\end{array}$ \\
\hline & In-Degree Centrality & The number of links to a vertex. \\
\hline & Out-Degree Centrality & The number of links from a node to other vertices. \\
\hline & Betweenness Centrality & $\begin{array}{l}\text { The number of times a node lies in the shortest path } \\
\text { between two other vertices. }\end{array}$ \\
\hline & Closeness Centrality & $\begin{array}{l}\text { The average length between a vertex and every other } \\
\text { in the network. }\end{array}$ \\
\hline & Eigenvector Centrality & $\begin{array}{l}\text { In this measure, if a vertex has links to other nodes that } \\
\text { are well connected, then the first node has a high value. }\end{array}$ \\
\hline
\end{tabular}

The results of this paper are visualised through network graphs drawn by NodeXL. The essential elements of network visualisation are the vertex and the edge. A vertex is also called a node, an agent, an entity or an item. The vertex can represent many things. Here, the vertex refers to a single post or a single comment within the Facebook fan page. An edge is known as a link, a tie, a connection or a relationship [45]. The edge refers to "the building blocks of networks" [45] (p. 35).

\section{Results}

First of all, this paper determined the overall metrics for the last three years of data drawn from the Suwon Hwaseong Fortress Facebook official fan page via NodeXL. The summarised results of graph metrics are presented below. 


\subsection{Characteristics of Vertices and Edges}

Table 2 shows that 2016 had a larger number of vertices and edges than 2017 and 2015. The results show that the headquarters of the Suwon Hwaseong fortress most actively promoted its event during '2016 Visit Year Suwon Hwaseong' with an increased number of posts or comments and relationships on the Facebook fan page. In this paper, the headquarters of the Suwon Hwaseong Fortress refers to the Suwon Cultural Foundation which was established and supported by the Suwon Municipal Government. For more information, see http:/ / english.swcf.or.kr.

Table 2. Number of vertices and edges of the Facebook fan page of the Suwon Hwaseong Festival.

\begin{tabular}{cccc}
\hline & $\mathbf{2 0 1 5}$ & $\mathbf{2 0 1 6}$ & $\mathbf{2 0 1 7}$ \\
\hline Vertices & 72 & 112 & 86 \\
Edges & 26 & 83 & 49 \\
\hline
\end{tabular}

Figure 8 presents the dynamics of vertices uploaded by looking at the monthly distribution of vertices. In 2015, from January to May, there were no vertices found, except for February. There was a significant increase in the number of posts between July to September. It reached a peak of 30 posts in July, and subsequently, the number of post in August and September decreased (18 and 16 posts, respectively). In 2016, there were no posts from January to February. Between March and April, the number of posts increased slightly. There was another increase in July, and the most significant rise occurred after September, with 65 posts in October. Afterwards, the number of posts fell sharply, so there waere no posts found in November and December. In 2017, the period between March and April saw a growth in the number of posts and a decrease again. Different from previous years, a couple of posts were found in May and June. From July to August, there was a slight increase. The most considerable rise was in September when the number of posts rose by 30. This peak was followed by a sudden drop of four posts over the next three months.

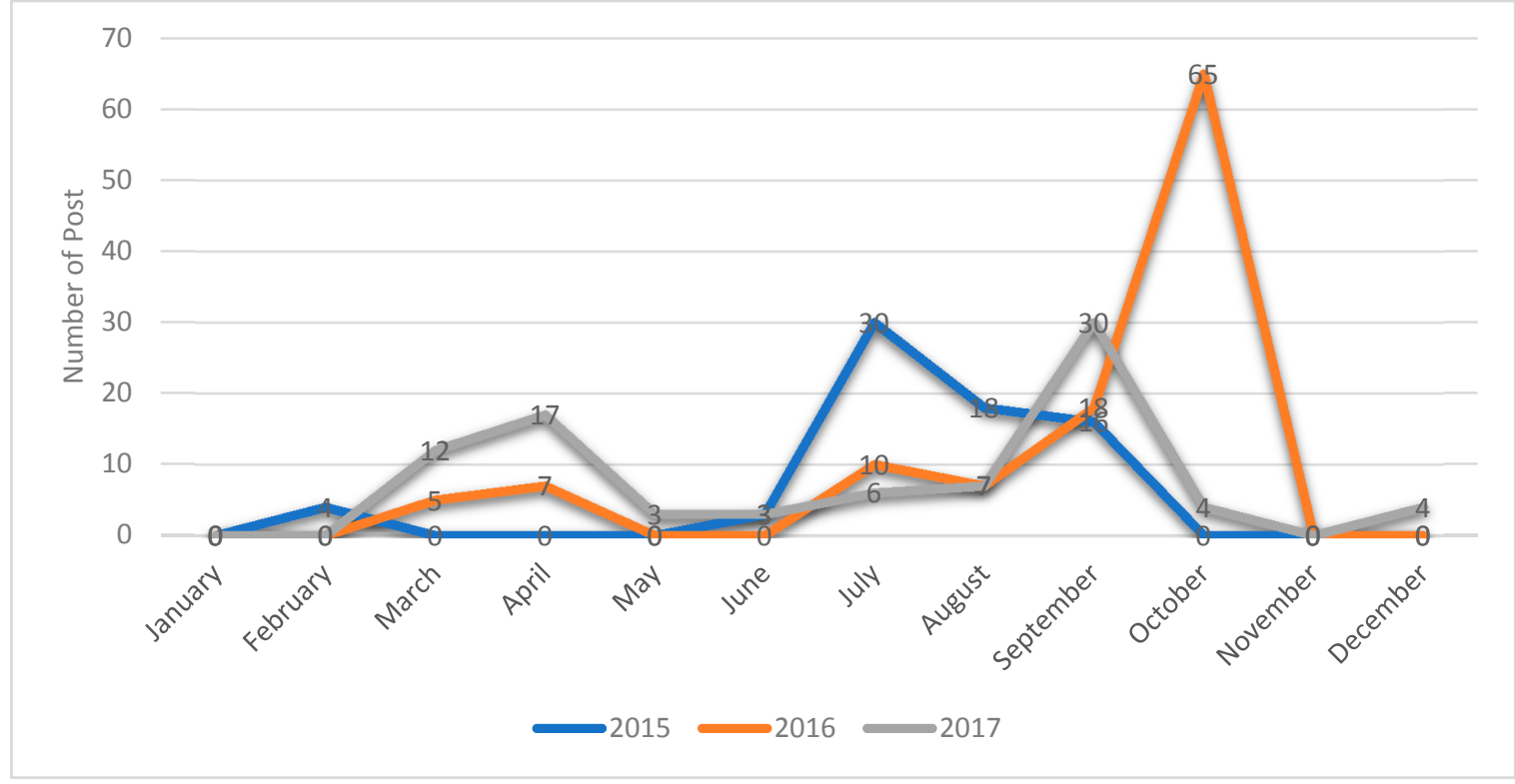

Figure 8. Monthly distribution of vertices.

In Figure 9, there are two different types of vertices-'comments' and 'posts'. The comments consisted of Facebook fan page viewers' mentions to the post uploaded by the Facebook fan page operator. The posts consisted of the Facebook fan page administrators' announcements to the viewers. 
Posts were presented in text, photo or video formats, or a combination of modes. Here, posts can be interpreted as efforts by the Suwon Hwaseong Facebook fan page operators to promote the event. Comments can be interpreted as the audience's interest in the Suwon Hwaseong Festival. Looking at the percentages over the last three years, the public interest in the Suwon Hwaseong Festival increased from 2015 to 2016 and decreased in 2017.

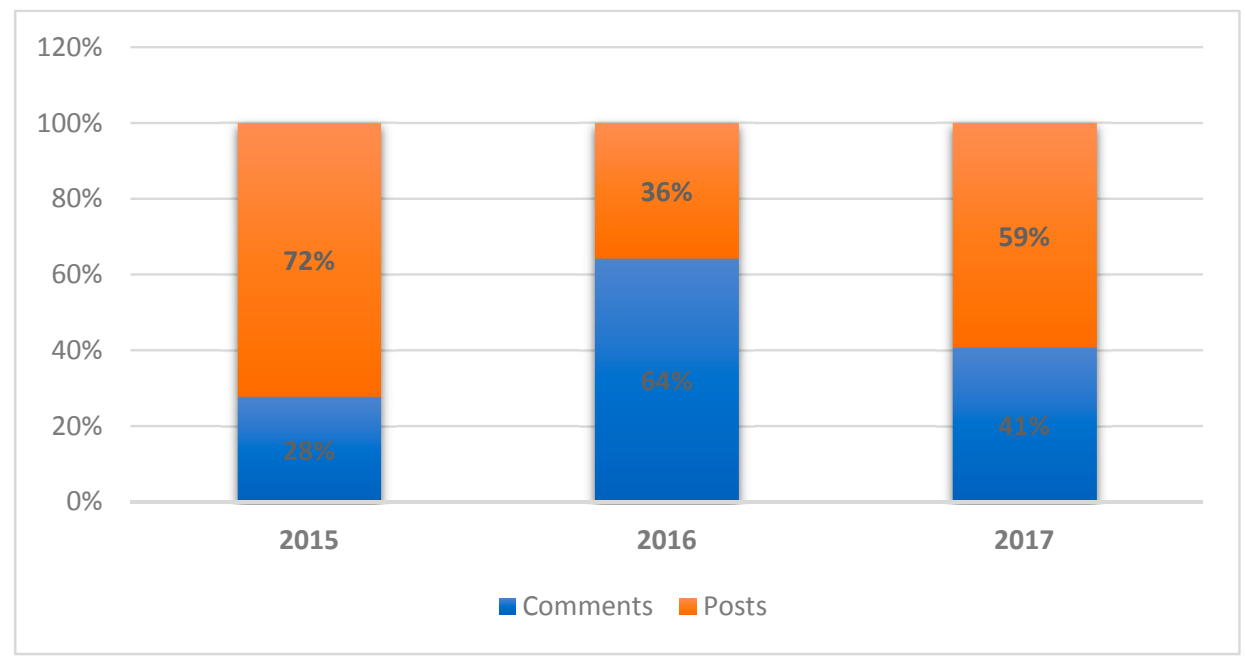

Figure 9. Vertice types (by the number of comments and posts).

To be more specific about the post types, the coder analysed the types of posts made by the Suwon Hwaseong Facebook fan page administrators. Over the last three years, the administrators mainly uploaded the posts in the combined format of photo and text. The remarkable point from Figure 10 was the increased percentage of video posts in '2016 Visit Year Suwon Hwaseong.' Comparing the results with Figure 10, the increased number of video posts increased the viewers' interest in the Suwon Hwaseong Festival. Despite there being a decrease in the percentage of video posts in 2017, the rate of video posts improved compared with the post types used in 2015. To show the degree of viewers' actual interest toward the posts in the Facebook fan page, Figure 11 provides some details about top posts by the number of likes.

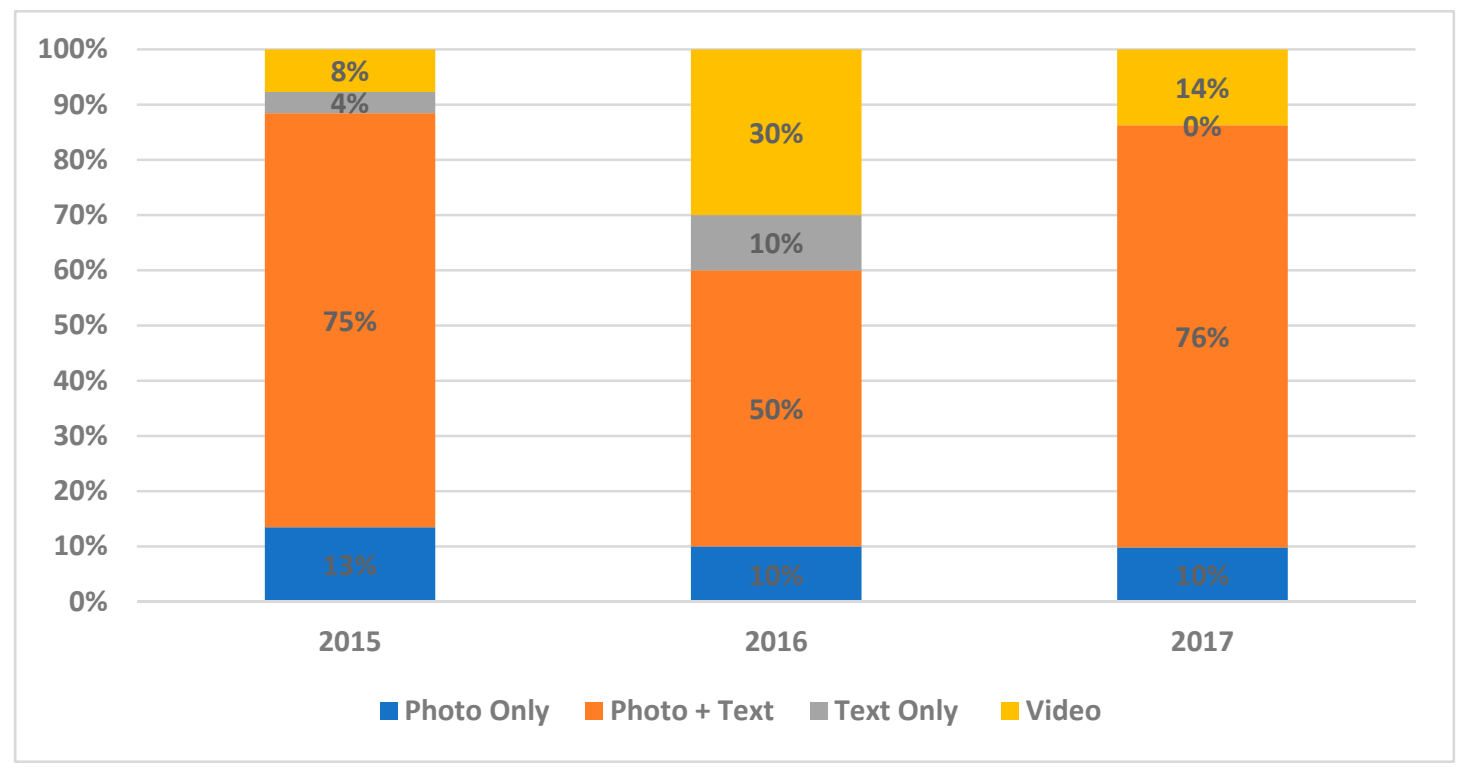

Figure 10. Post types. 


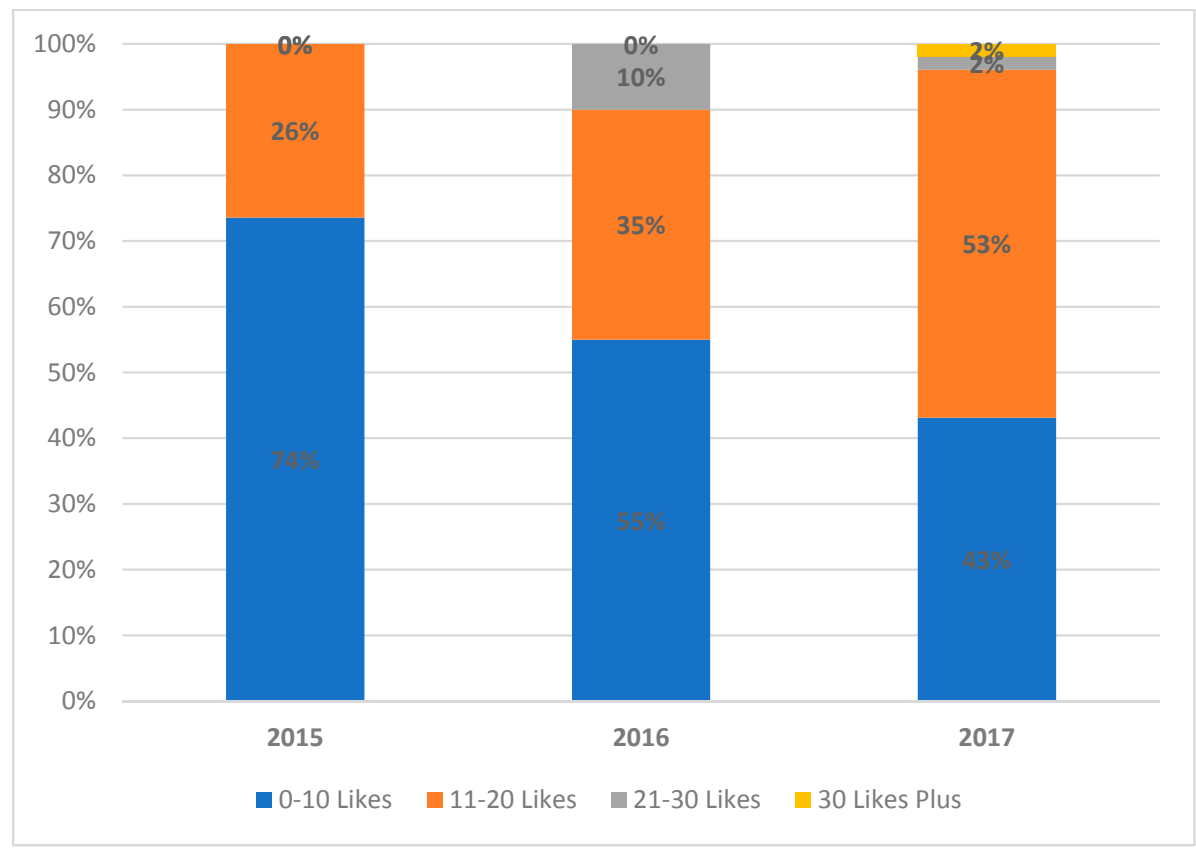

Figure 11. Top posts by likes.

To explore the viewers' interactions with the posts on the Facebook fan page, the coder investigated the number of viewers who hit the like buttons to the Facebook posts by using NodeXL. In 2015, 75\% of posts in Facebook Fan Page had 0 to 10 likes. The percentage of the posts with $0-10$ likes decreased in subsequent years. From 2016, the Suwon Hwaseong Facebook fan page's posts succeeded in drawing viewers' interactions. Paralleling the results of post types, an increased percentage of video posts might be the main factor that raised the number of viewer responses. Subsequently, Figure 12 presents the themes of the posts in Suwon Hwaseong Facebook fan page.

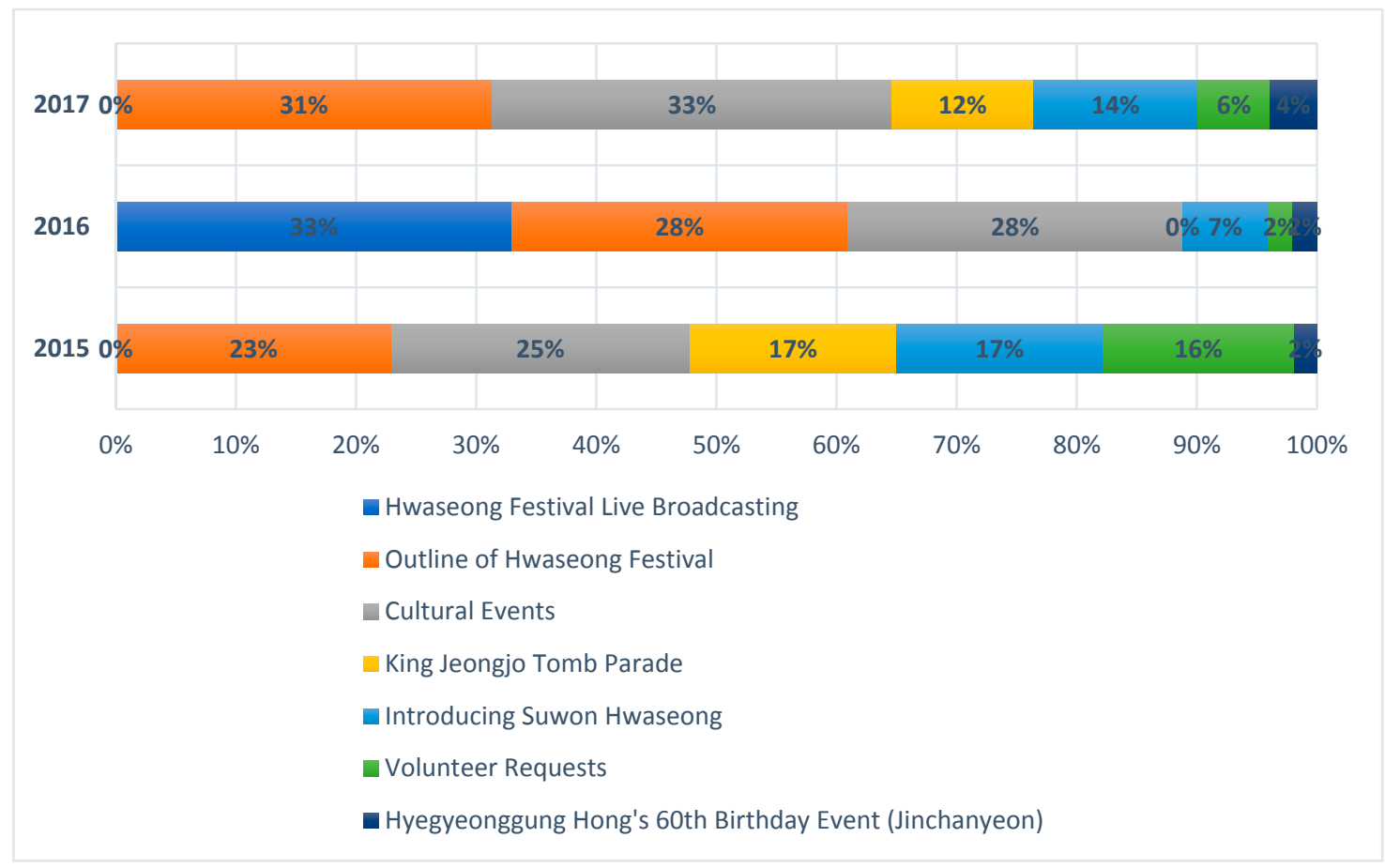

Figure 12. Themes of the posts. 
The themes of the posts indicate the range of information that the Suwon Hwaseong Facebook fan page headquarters wanted to share with their viewers. The central theme of the Facebook fan page posts shows the page administrators' priorities for promotion strategies. The results show that the Facebook fan page administrators emphasised different themes for each year. In 2015, the page administrators focused on delivering the outline of the Hwaseong Festival by introducing the King Jeongjo Tomb Parade, Hyegyeonggung Hong Jinchanyeon-King Jeongjo's Mother's 60th birthday party, martial arts performances and participatory events. In 2016, the page administrators were inclined to post live broadcastings covering Hwaseong Festival events, like the eve of the festival or the opening ceremony of the festival. These live video posts resemble a technique of the traditional media: spot news reportage. McPherson suggested that spot news treats news reported on events as they happen as more important than others [46]. Spot news also emphasises the speed of information diffusion to the audience [46]. Based on this technique, the Facebook page administrators were able not only to rapidly spread event information to the viewers but also to lead the viewers' instant responses or interactions about the event. In 2017, the Facebook fan page administrators focused on delivering information on the diverse cultural events of Hwaseong Festival. For instance, festivals and children's plays were the examples of theatrical events. The experience event on King Jeongjo for children, the Joseon handicraft workshop, the Hwaryeongjeongoyubyeoldarye (tea ceremony) and Mudeungnori (dancing on another dancer's shoulders) were historical events. Flying Suwon, Velo Taxi, the Humanities Academy, concerts and performances were other events. Except for these three main events, Hwaseong Festival's Facebook fan page was devoted to covering historical figures, such as King Jeongjo of Joseon and Lady Hyegyeonggung Hong (King Jeongjo's mother) and Suwon Hwaseong.

\subsection{Network Centrality Measures of the Suwon Hwaseong Facebook Fan Pages}

Table 3 shows the overall graph metric values of the Facebook fan page of the Suwon Hwaseong Fortress. At the level of the aggregate network, the density of the network formed in 2015 increased in 2016 and 2017. The high density could indicate critical sociological ideas, like cohesion, solidarity and membership [45]. Due to the active promotion of visiting Suwon Hwaseong in 2016, the members who put the posts on Facebook might have had a closer relationship with other members of the society than 2015. The average geodesic distance indicates how close community members are from one another [45]. When the value is more prominent, the members of the network do not have close relationships with each other. When the amount is smaller, the members of the network have more intimate relationships with each other [45]. Looking at the results in Table 3, the members of the network formed in 2015 and 2017 might have had closer relations than those formed during 2016.

Table 3. Graph metrics (due to long decimal values in density and average geodesic distance, the authors of this paper agreed to round to the fourth decimal place).

\begin{tabular}{ccccc}
\hline & & $\mathbf{2 0 1 5}$ & $\mathbf{2 0 1 6}$ & $\mathbf{2 0 1 7}$ \\
\hline \multirow{3}{*}{ Aggregate Network Metrics } & Density & 0.0051 & 0.0067 & 0.0067 \\
\hline & Average Geodesic Distance & 1.0598 & 1.5346 & 1.1515 \\
\cline { 2 - 5 } & Average In-Degree Centrality & 0.361 & 0.741 & 0.570 \\
\cline { 2 - 5 } Vertex-Specific Metrics & Average Out-Degree Centrality & 0.361 & 0.741 & 0.570 \\
\cline { 2 - 5 } & Average Betweenness Centrality & 0.5 & 4.411 & 0.977 \\
\cline { 2 - 5 } & Average Closeness Centrality & 0.183 & 0.244 & 0.238 \\
\cline { 2 - 5 } & Average Eigenvector Centrality & 0.014 & 0.009 & 0.012 \\
\hline
\end{tabular}

Regarding the vertex-specific metrics, this paper observed the values of Degree Centrality, Betweenness Centrality, Closeness Centrality and Eigenvector Centrality. In regard to the Degree Centrality, since this graph was directed, NodeXL could not calculate the value of Degree Centrality. This paper looked at the levels of In-Degree and Out-Degree as well. The In-Degree measures the number of edges 
that point toward the vertex of interest. In the case of the Suwon Hwaseong Facebook fan page, when the value of In-Degree was high, the popularity of the event was high. When the Out-Degree value was high, this indicated that the leading actor of the network was making efforts to promote the event. A shown in Table 3, the popularity and promotion of Suwon Hwaseong were the highest in 2016 (0.741). This means that Suwon city not only actively promoted this event to its audience but also gained the audience's support for the Festival. For the values of Betweenness Centrality and Closeness Centrality, the network formed in 2016 had the highest values. The value of Betweenness Centrality (4.411) shows the network's impact on the information flow process. It shows that Suwon city had the highest control in terms of disseminating messages to their audience [47]. The value of Closeness Centrality (0.244) shows the level of information diffusion among the members of the network. This means that the Suwon Hwaseong Festival Facebook fan page administrators quickly diffused their messages to their viewers [47]. Regarding the Eigenvector Centrality, the network formed in 2015 had the highest value, and the network formed in 2016 had the lowest value (0.009). The Eigenvector Centrality is calculated by applying the weights and other vertices' centralities, and it shows the level of connection to influential vertices rather than isolated ones [45]. This means that the Eigenvector Centrality value will become bigger when the vertices are connected to other nodes with higher centrality [47] (p. 56). The lowest value, which occurred in 2016, means that the vertices were not connected to other vertices with higher centrality. This value proves that Suwon city performed the most active and centralised information difussion strategy in 2016. The headquarters had higher control and consistency in terms of the information difusion process. Thus, Suwon city played a dominant role in the Facebook promotion of this event.

\subsection{Visualised Social Networks and Semantic Networks}

Figure 13 presents visualised networks of Suwon Hwaseong Facebook fan page on a yearly basis. In 2015, the network had a simpler structure than the networks formed in subsequent years. The network in 2016 had the most tangled structure. Considering the Geodeic Distance results of, the Suwon Hwaseong Facebook fan page administrators succeeded in establishing the most extended network in 2016. Based on the number of likes in Figure 10, this paper considers that the headquarters' event promotion actively utilised Facebook as a branding tool for the Suwon Hwaseong Festival. Regarding the network structure, the Suwon Hwaseong Facebook fan page administrators showed weaker efforts in promoting the Suwon Hwaseong festival after '2016 Visit Year Suwon Hwaseong.' To accomplish firmer city branding, the practitioners of city promotion should pay more attention to providing more varied posts which promote visual attractions, for example, using more video or live broadcasts to the audience.

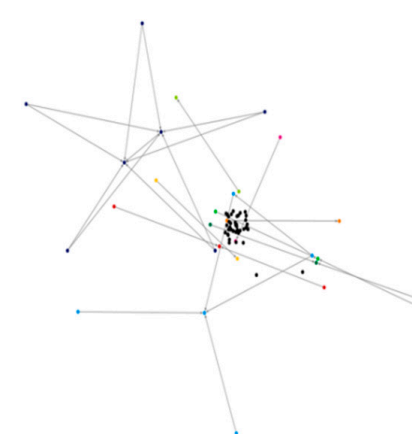

(a)

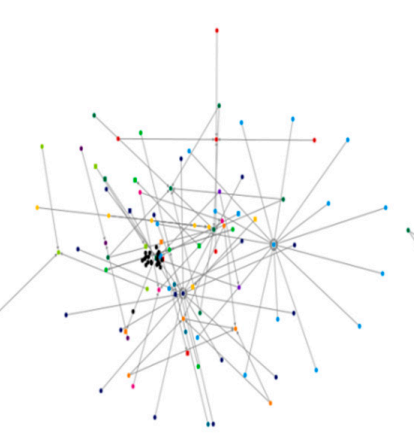

(b)

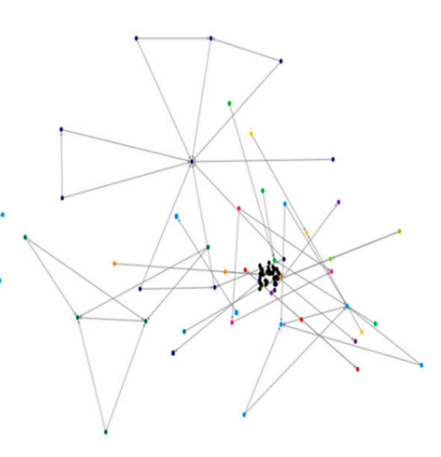

(c)

Figure 13. Visualised networks of the Suwon Hwaseong Facebook fan page: (a) 2015, (b) 2016, (c) 2017.

Another impressive aspect found in Figure 13 is the structural openings in the networks formed from 2015 to 2017. On one hand, structural openings were found in the networks formed in 2015 and 
2016. On the other hand, there was a smaller number of structural closure in the network formed in 2017. Burt explained such openings as structural holes which refer to the empty spaces in the social networks [48]. Within groups of two or more people, when there is a structural hole, a specific actor at the centre plays a bridging or mediating role regarding information shared within the network [49]. This structural opening means that no redundant information dissemination occurs among the nodes within the network. Consequently, this structural aspect shows the effectiveness of the information diffusion process. The decrease in structural holes in the network formed in 2017 means that there was neither a gatekeeper, nor an effective information provider, within the network. Within this network closure, redundant information would have been shared in 2017.

To presenting the keywords used in the Facebook posts on the Suwon Hwaseong fan page, this paper explored semantic networks by NodeXL by using the function of word pairs. To group the keywords in the posts, some groups of vertices were presented in different colours and different shapes (circles or squares). Although small numbers of vertices were found in 2015 and 2017, there was a diverse range of main themes found. The results are presented in Figures 14-16.

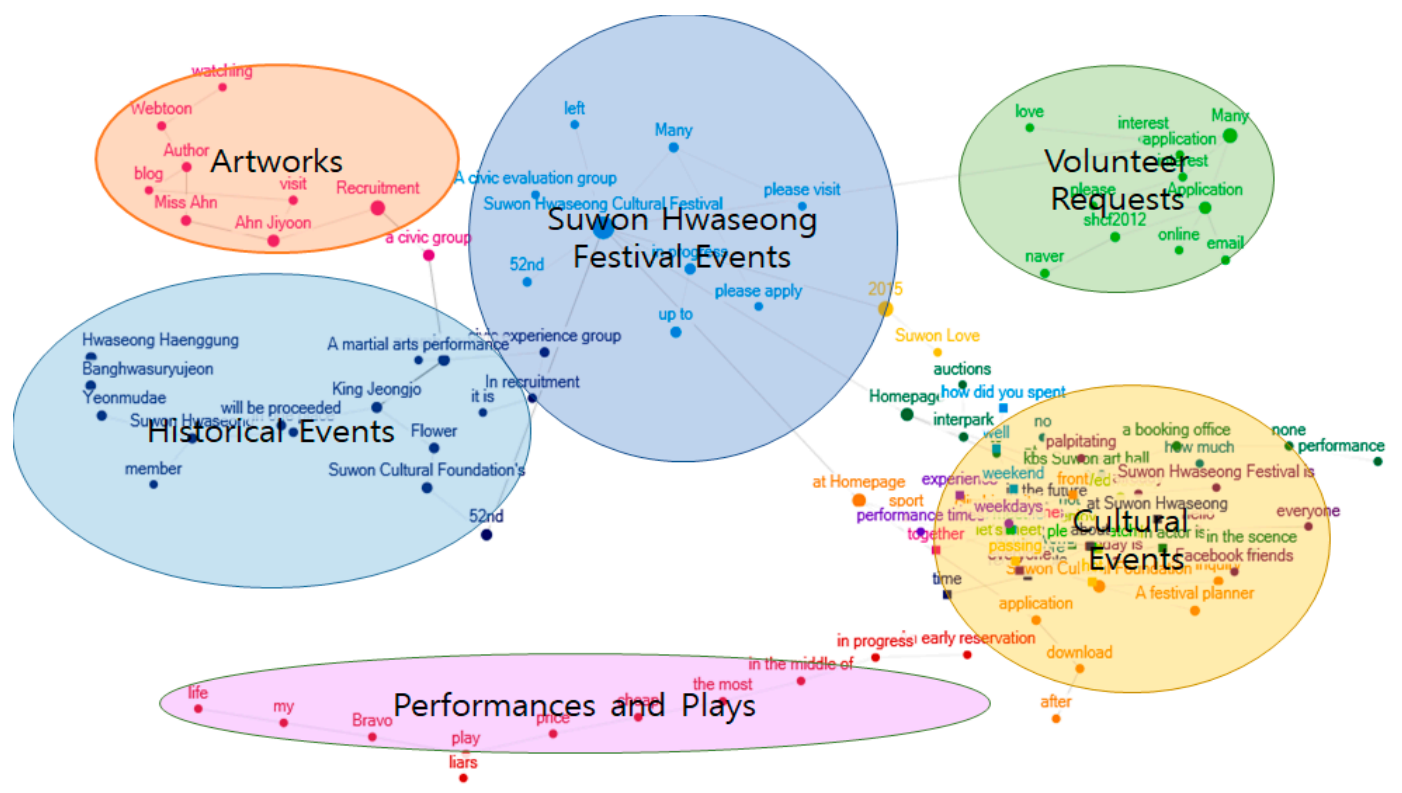

Figure 14. The Facebook fan page's semantic network formed in 2015.

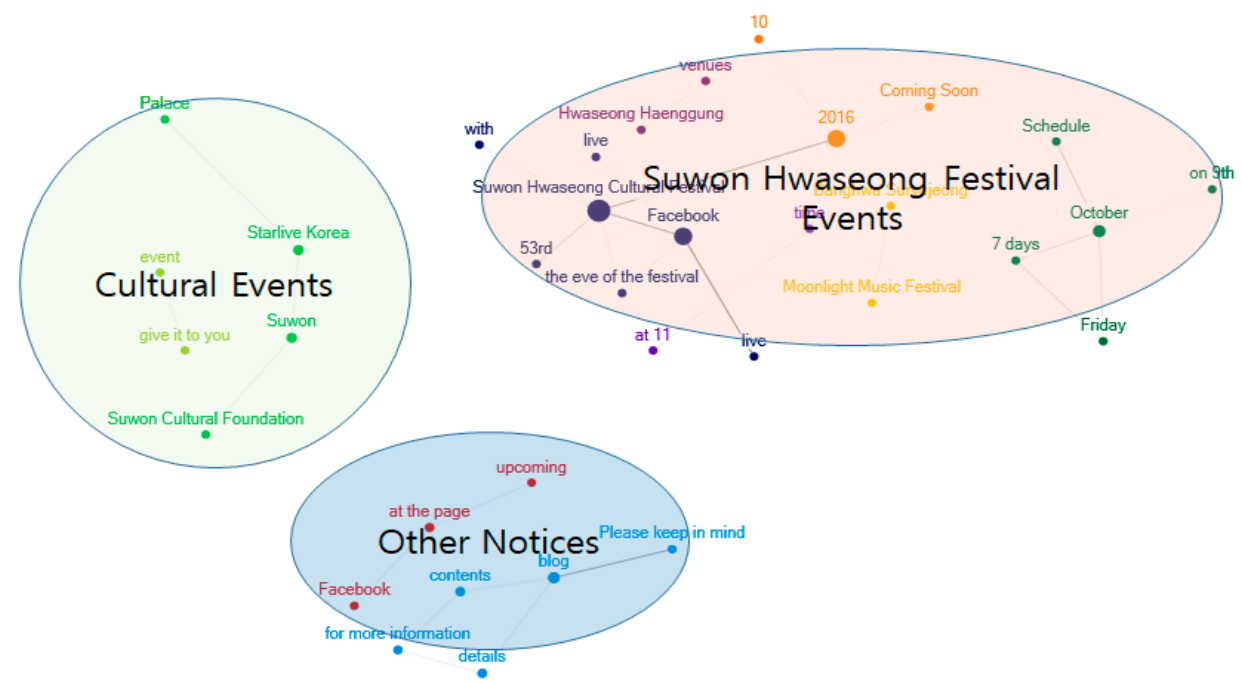

Figure 15. The Facebook fan page's semantic network formed in 2016. 


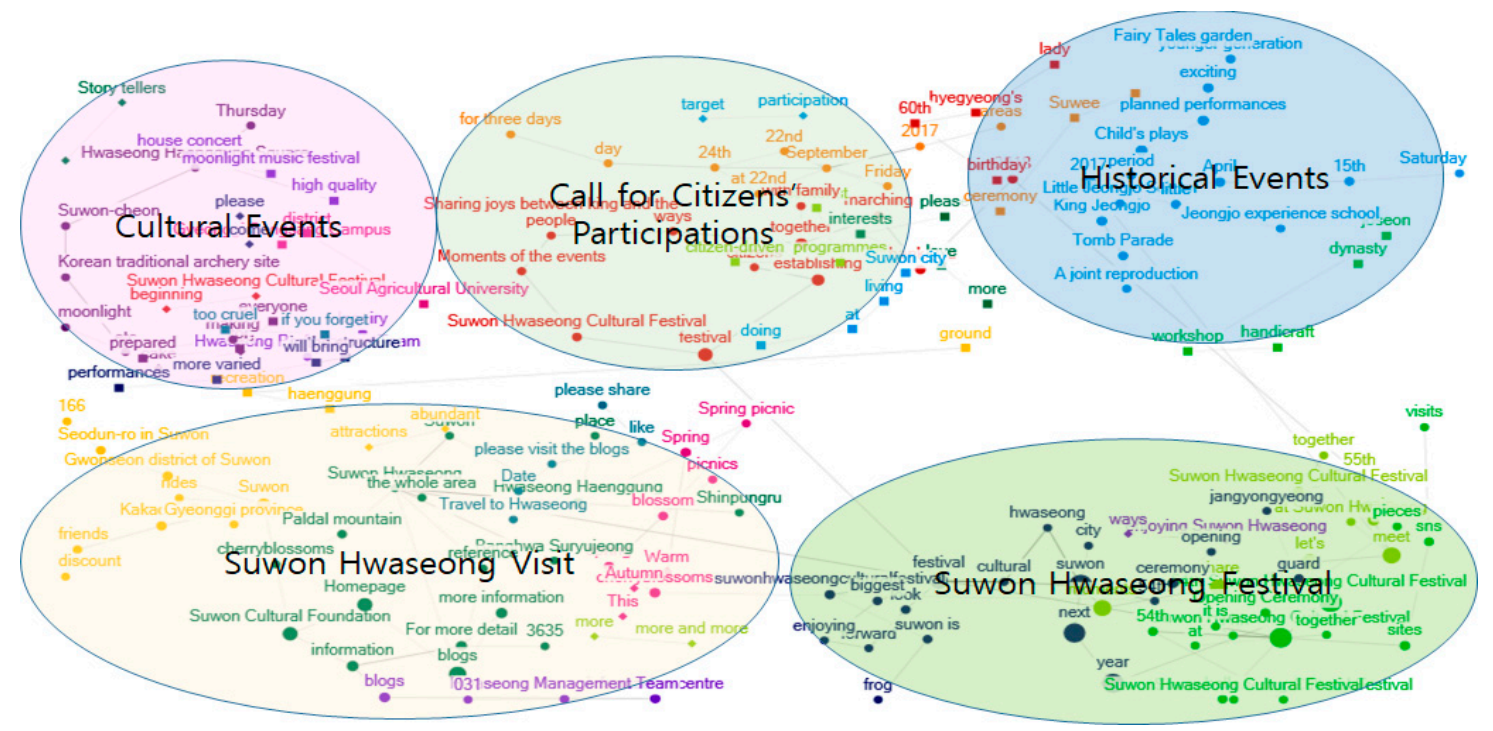

Figure 16. The Facebook fan page's semantic network formed in 2017.

As for 2015, Figure 14 shows that there six primary themes were found: artworks, historical events, Suwon Hwaseong festival events, volunteer requests, cultural events and performances and plays. As for 2016, Figure 15 suggests there three main themes were found: cultural events, Suwon Hwaseong festival events and other notices. As for 2017, Figure 16 presents the five major themes in the network: cultural events, Suwon Hwaseong visit, call for citizen participation, historical events and the Hwaseong Festival. After comparing the key themes in the semantic networks from 2015 to 2017, this paper obtained several findings. First, in 2016, the Hwaseong Festival Facebook fan Ppage administrators disseminated events intensively to their audiences. By comparing some vertices and semantic networks, the coder could not determine the diverse range of semantic themes in the network. In this regard, the campaign headquarters intensively employed a selected range of information about the Suwon Hwaseong festival. Second, except for 2016, the festival headquarters continuously sought volunteers for the event. This finding shows that there might be a low percentage of citizen participation in this event. Third, historical events were less emphasised than cultural events. Despite the importance of Suwon Hwaseong's cultural heritage, the campaign headquarters does not seem to have adequately promoted the historical value of Suwon Hwaseong to the audience of the Facebook fan page.

\section{Discussion}

The results of semantic network analysis enabled us to see aspects of Suwon city's promotion pattern in social media, such as the content, frequency and format of promotion. Also, the results show the information diffusion pattern regarding the event. However, it is essential to examine the practicality of the results in order to draw out their substantial meanings. We will therefore conduct more in-depth discussion based on Suwon city's qualitative assessment reports.

Within the data collection period of 2015-2017, the year 2016 was the central year in terms of showing the highest control of promotion activity. However, we were able to determine some problems when we compared the results based on our quantitative analysis and the results from Suwon city's self-assessment qualitative analysis. There are two moments to be addressed. First, there was a mismatch between the target media for the promotion strategy. Since 2011, Suwon city has prepared and promoted '2016 Visit Year Suwon Hwaseong', which is an important cultural event [50]. Suwon city published an assessment report of this event based on a public opinion survey of 1000 respondents. They were asked "how did you find information about the main events." Words-of-mouth $(21.8 \%)$ was the main source of information, followed by portal sites $(14.7 \%)$, outside advertising 
(14.5\%), blogs or SNS (12\%), television (6.7\%) and newspapers (4.2\%) [51]. According to the report, Suwon city hosted the Gyeonggi Suwon Airshow 2016, the Asia Model Festival in Suwon 2016, the Suwon K-Pop Super Concert, the Suwon Ballet Festival, Yurangmerang Paldo Hanmadang and the King Jeongjo Tomb Parade and Exhibition for the main events of 2016 [51]. For the first three events, word-of-mouth was a major source of information: Gyeonggi Suwon Airshow 2016 (24.3\%), Asia Model Festival in Suwon 2016 (40.7\%) and Suwon K-Pop Super Concert (27.4\%) [51] (pp. 89-90). In the case of the King Jeongjo Tomb Parade, respondents mentioned that the event homepage was their main source of information (22.8\%), followed by word-of-mouth (17.4\%) [51]. However, the budgetary allocation for promotion was implemented differently. In 2016, Suwon city allocated the largest budget to newspaper/magazine advertisement (364.7 million KRW), television (138.6 million KRW), SNS (95.7 million KRW) and outside advertising (169.7 million KRW) [51] (p. 13). Comparing this point with the budgetary allocation of promotion, we identified that the budget was not effectively distributed to the promotion tools. The results imply the disparity between the promotion strategy and the promotion effect. Furthermore, such difference also indicates that the effect of promotion would not have been impressive. Also, in forming the promotion strategy, the headquarters need to devote more effort to using social media and other types of sustainable measures.

Second, there was an insufficiency in the Suwon city's systematic promotion strategy. Based on the strengths and weaknesses of Suwon city's promotion of the events, we would like to give some suggestions for further improvement. These suggestions can be classified into two aspects-in terms of hardware and software. For the hardware perspective, this paper would like to suggest an upgrade of current existing internet promotion by establishing a portal site that incorporates links to the event homepage, blogs and Facebook, Twitter or Instagram event pages. By doing this, Suwon city will be able to manage these internet platforms more effectively. On one hand, the Suwon Ballet Festival was managed by Gyeonggi Cultural Foundation homepage [52]. On the other hand, the Gyeonggi Suwon Airshow 2016, the Suwon K-Pop Super Concert, and the Asia Model Festival were managed by the Suwon city hall homepage [53]. In other words, the headquarters did not promote the events collectively. Looking at Figures 12 and 15, the contents of such events were not detected on Facebook fan page posts. There was a huge difference in the events promoted in each year, and this point corresponds to the verification of Hypothesis 6 (H6). Second, Suwon city needs to establish a control tower to allow more effective promotion of the event. In Suwon city's interview, Hong Sajun, the governor of Jangan District of the Suwon, said that "the promotion would be more effective when the Task Force Team for '2016 Visit Year Suwon Hwaseong' was established in 2011. [ . . . ] I am quite ashamed that Task Force Team was established in August 2016" [50]. Afterwards, he emphasised the importance of establishing an effective Task Force Team to facilitate systematic promotion of the event" [50].

In terms of a software perspective, first of all, Suwon city should adopt a more systematic and comprehensive management system for the contents of the festival. Figure 12 shows that the main themes of festival events were the King Jeongjo Tomb Parage, the Suwon Hwaseong Festival Overview and the Introduction of Suwon Hwaseong. Looking at Suwon city's report, this paper was able to determine the strength of the Suwon city's promotion strength by looking at a diverse range of events, including the Gyeonggi Suwon Airshow 2016, the Asia Model Festival in Suwon 2016, the Suwon K-pop Super Concert, the Suwon Ballet Festival, the 20th Suwon Theatre Festival, the Suwon Jazz Festival, the 2016 Suwon Foreign Students Culture Festival, and the 4th World Humanities Forum [50]. Despite such diversity, the strength of this event was not well addressed on the Facebook fan page. This means that Suwon city unintentionally did not fully promote the events. Second, Suwon city should establish a new promotion strategy. In regard to sources of information used, the portion using SNS has increased significantly. Furthermore, looking at the 2016 case, most visitors of to the event were female (61\%) rather than male (39\%) [51] (p. 131). Looking at the visitors' social statuses, most visitors were students (23.1\%) and housewives (21.4\%) [51] (p. 137). Considering the aforementioned high penetration rate of smart phones use in Korea (see Figure 1), the Suwon government should pay 
more attention to SNS promotion. In addition, developing a smartphone application for this event could be another helpful breakthrough.

\section{Concluding Remarks}

To summarise, this paper attempted to look at diverse aspects of the social network formed by a Facebook fan page to assess Suwon city's place branding strategies. In the first part, involving characteristics of vertices and edges, we had three main findings. First, the number of vertices shows that there were fluctuations between years (2015 low, 2016 high and 2017 low again). This trend shows that the headquarters of Suwon Hwaseong Festival were devoted to delivering the message to the audience in '2016 Visit Year Suwon Hwaseong'. Also, in 2016, in contrast to the post decrease, the number of comments increased. This means that the audience paid more attention to the event held in 2016. Second, the type of posts indicates that the festival headquarters were devoted to utilising diverse modes of communication by increasing percentage of live video of Suwon Hwaseong Festival presented to the audience. Through the increased number of 'likes' in 2017, we believe the audiences showed their preference for posts on the Facebook fan page. Third, the themes suggested by the Facebook Fan Page show that the Hwaseong Festival Overview was the festival headquarters' main focus for their uploaded posts. Given the contents, the festival headquarters was more likely to cover cultural features than historical ones. In the second part of the study, which concerned the network centrality measure at the aggregate level of networks over time, the density was shown to increase over the research period, and this showed the close relationships between the vertices of the network. At the vertex-specific level of networks, information diffusion was rather weak. In the last part of the study, we looked at the structures of visualised social networks and semantic networks formed from 2015 to 2017. In 2016, we were able to find the structural holes in the social network of Facebook fan page. Subsequently, we found that these structural holes were filled in 2017, and referred to an ineffective information sharing process in which redundant messages were circulated among the members of the network. Regarding the semantic network, we consider that the festival headquarters delivered intensive messages to the audience in 2016. This finding suggests that intensive and coherent messages can be the key to having an effective strategy for place branding and promotion. Similar to the themes of the posts, the areas of cultural event-related keywords were more prominent than those of historical issues or events regarding Suwon Hwaseong.

Based on these findings, this paper can answer the research questions as follows. For the first research question (Q1), the features of Suwon Hwaseong Facebook fan page's postings were shown from the characteristics of the vertices, such as vertices types, number of likes to the posts and the themes of the posts. For the second research question (Q2), in 2016, the Suwon Hwaseong Facebook fan page headquarters performed centralised and concentrated pro-active management of event promotion to the audience considering structural holes. However, this concentrationscould not last consistently. For the last question (Q3), the semantic networks of the Suwon Hwaseong Facebook fan page presented the range of thematic framings from the vertices (comments and postings). The headquarters released the diverse range of semantic themes to the audiences in 2015 and 2017 compared with the year 2016. However, the ranges of semantic themes provided were similar to one another. In this regard, searching for new themes will be another significant task for the Suwon city.

Subsequently, this paper can verify the hypotheses above based on the findings. The first hypothesis (H1) is accepted. The result shows that the year 2016 had the highest number of vertices compared with the previous year and the following year. The second hypothesis $(\mathrm{H} 2)$ is not accepted because each year had a different peak month. In 2015, July was the peak month, which is three months away from the event (8-11 October 2015). In 2016, October was the peak month, which is the month of the event (7-9 October). In 2017, the same as the previous year, September was the peak month (22-24 September 2017). This paper could not find out the suitable reason why 2015 had a different peak month. In general, the Suwon Hwaseong Facebook fan page was more inclined to upload more postings than other months over the year. The third hypothesis (H3) is accepted due to the highest 
density of the social network being formed in 2016. However, this hypothesis should only be partially accepted because the value of density in 2017 was identical. In contrast to three previous hypotheses, the fourth hypothesis (H4) is not accepted. The results of centralities showed that the administrators could not maintain the best quality of network connections among the members. The fifth hypothesis (H5) is accepted. The Suwon Hwaseong Facebook fan page administrators maintained the highest information diffusion efficiency in 2016 because of the circulation of non-repetitive or non-redundant messages within the network. The last hypothesis (H6) is not accepted. Suwon Hwaseong Facebook fan page did not distribute a diverse range of themes in their postings during the year 2016.

In 2016, Suwon city evaluated this event as being successful in terms of the increase in visitors and their expenditure in Suwon [51] (p. 259, p. 263). However, in terms of a sustainable promotion strategy, there are two aspects which needs to be improved. First, our results showed that the headquarters showed a concentrated effort to promote the event to the audiences. Looking at the structural holes filled in 2015 and 2017, we believe the headquarters' efforts to promote the event were inconsistent. Considering the results in Figures 13 and 16, we were able to determine that the headquaters' promotion strategy was less centralised and controlled by looking at the similar values found in years 2015 and 2017. In this regard, we cautiously estimate there have been some recurrent problems in terms of maintaining sustainable city branding strategy. Second, the headquarters should determine appropriate themes and promotion strategies to guarantee sustainable city branding. As we mentioned above, the historical themes should be revisited. The respondents mentioned that they visit Suwon mainly because of Hwaseong Haenggung (location) (56.8\%) and Suwon Hwaseong (architecture) (56.4\%), which were the most memorable places [51]. Their reasons for visiting Suwon are for historical and cultural experiences (33.1\%) [51]. Unfortunately, the results of semantic network show that the historical themes were not properly emphasised. To maintain sustainable city branding, these landmarks should be central assets for the Suwon city. Against this backdrop, Suwon has established its city brand as a historical and cultural city. In order to enhance such image and guarantee the sustainable promotion strategy, establishing timely and systematic promotion strategies is essential. To obtain a sustainable city branding promotion strategy, SNS is the appropriate means of promotion.

As the empirical literature has indicated, social networks embedded in social media could show the importance of place branding. The social network analysis also showed the current stage of place branding strategies, which will lead to the further suggestions to the municipal government. In this regard, this paper would like to give three suggestions. First, the event headquarters or decision makers should work hard on a way of determining a more diverse range of themes to promote the Suwon Hwaseong Festival. The current strategy does not draw a sufficient number of participants or followers to the events. Also, despite the increase in the number of volunteers in 2016, the residents' attention seems to be temporary. The headquarters should work hard to find new semantic themes to attract more volunteers to the event. Second, the headquarters should work hard on managing the quality of their networks. Given the structural hole, the information diffused in 2017 seems to be somewhat redundant. In order to overcome this problem, the local government should find some helpful and unique information to disperse to the audience of the event. Finally, the headquarters should continuously put effort into guaranteeing a constant number of postings. The peaks, for instance, were usually found in September and October. This finding shows that the headquarters is not showing a constant effort towards promote the event. Thus, to achieve sustainable place branding, strategic management and efforts are the most urgent tasks.

Author Contributions: S.-W.Y. conceptualised the theme of the paper, wrote the introduction and the literature review of the paper, and complemented the discussion and conclusion. S.W.C. collected the data, designed the methodology of the article, undertook the analysis with using the software and worked out the draft of the discussion and conclusion. Both authors contributed equally in terms of preparation of the manuscript.

Acknowledgments: This work was supported by a Korea University Grant in 2018.

Conflicts of Interest: The authors declare no conflict of interest. 


\section{References}

1. Kim, D.; Hwang, E. Light and Darkness of Urban Regeneration: Culture-centred City Regeneration of the Hoxton Region in London. In Proceedings of the 2013 International Conference of the Korean Association of Policy Studies, Yonsei University, Seoul, Korea, 14-15 June 2013; Volume 1, pp. 329-344. (In Korean)

2. Korea Internet \& Security Agency. Internet Usage Statistics. Available online: https://isis.kisa.or.kr/ statistics/?pageId=020200 (accessed on 28 March 2018). (In Korean)

3. Ministry of Science and Information Technology. Press Release, 2017 Internet Usage Statistics Released. Available online: http:/ / www.msit.go.kr/web/msipContents / contentsView.do? cateId=mssw311\&artId= 1374306 (accessed on 28 March 2018). (In Korean)

4. Kaplan, A.M.; Haenlein, M. Users of the World, Unite! The Challenges and Opportunities of Social Media. Bus. Horiz. 2010, 53, 59-68. [CrossRef]

5. eMarketer, eMarketer Chart. Primary Social Media Platform Used by Social Media Users in South Korea, 2016 \& 2017 (\% of Respondents). 23 August 2017. Available online: http:/ /www.emarketer.com/Chart/PrimarySocial-Media-Platform-Used-by-Social-Media-Users-South-Korea-2016-2017-of-respondents / 210301 (accessed on 28 March 2018).

6. UNESCO World Heritage Portal. Available online: http://whc.unesco.org/en/list/817 (accessed on 24 March 2018).

7. Lee, E. Korean History 15: Cultural Monarch Jeongjo; Hangil-sa: Seoul, Korea, 2001; ISBN 8935651540. (In Korean)

8. Google Map. Suwon-si Gyeonggi-do. Available online: https://www.google.co.kr/maps/place/Suwon-si, +Gyeonggi-do/@35.8092304,127.0438222,7.18z/data=!4m5!3m4!1s0x357b430a20764611:0xf1373002ee5db4c9!8m2! 3d37.2635727!4d127.0286009 (accessed on 6 May 2018).

9. Medical Korea. Attractions, Suwon Hwaseong Fortress. Available online: http://www.koreamedical.or.kr/ en/gmeditour-tour/suwon-hwaseong-fortress / (accessed on 6 May 2018).

10. Hwaseong, How to Win the World Recognition? OhMyNews. 18 September 2006. Available online: http: / / www.ohmynews.com/NWS_Web/view / at_pg.aspx?CNTN_CD=A0000360523 (accessed on 28 May 2016). (In Korean)

11. Kim, B. Kim's Story on Korean Architecture 1; Dolbege: Seoul, Korea, 2006; ISBN 8971992328. (In Korean)

12. Suwon Cultural Foundation. Hwaseong Fortress: Facility Information, Janganmun (the North Gate). Available online: http: / / english.swcf.or.kr / p p=34\&mode=view\&idx=328\&rIdx=99999210 (accessed on 24 March 2018).

13. Suwon Cultural Foundation. Available online: http: / / english.swcf.or.kr $/$ ? $\mathrm{p}=34 \&$ mode $=$ view\&idx $=55 \&$ rIdx=99999837 (accessed on 24 March 2018).

14. Suwon Cultural Foundation. Hwaseong Fortress: Introduction. Available online: http://english.swcf.or.kr/ ?p=31 (accessed on 24 March 2018).

15. Kim, J. Activation of the Suwon Hwaseong Cultural Content Based on the Joseon Royal Records. Hum. Contents 2014, 34, 213-237.

16. Suwon Cultural Foundation. Suwon Hwaseong Festival. Available online: http:/ /www.swcf.or.kr/?p=86 (accessed on 7 May 2018). (In Korean)

17. Suwon Cultural Foundation. A Time Travel with King Jeongjo 220 Years ago, 52nd Suwon Hwaseong Festival Monarch Procession Volunteer Recruitment. Available online: http://blog.naver.com/PostView.nhn?blogId= swcf_kr\&logNo=220407112645\&parentCategoryNo=\&categoryNo=31\&viewDate=\&isShowPopularPosts= true\&from=search (accessed on 7 May 2018). (In Korean)

18. Seoul Changdeokgung Suwon Hwaseong-King Jeongjo Is here. Incheon Daily. 10 October 2016. Available online: http:/ / www.incheonilbo.com/?mod=news\&act=articleView\&idxno=729910 (accessed on 7 May 2018). (In Korean)

19. Reenacting the whole Route of Jeongjo Monarch Process, Seoul-Suwon-Hwaseong $59.2 \mathrm{~km}$. Asia Economy. 23 September 2017. Available online: http://www.asiae.co.kr/news/view.htm?idxno= 2017092114545156372 (accessed on 7 May 2018). (In Korean)

20. Kang, I. A Study on the Characteristics of Planning of Hwa-sung from the Point of Water System. J. Korean Inst. Tradit. Landsc. Archit. 2011, 29, 137-147. (In Korean) 
21. Ahn, K. Suwon Hwaseong World Heritage Registration and Its History. Architecture 2015, 59, 48-55. (In Korean)

22. Shim, S. Korea Culture's honour and introspection in 21 Century. Hum. Contents 2006, 8, 197-213. (In Korean)

23. Shim, S. The Meaning of Urban Regeneration through the Restoration and the Representation of Historical Spaces: Focusing on the Hwaseong Fortress. Hum. Contents 2012, 25, 39-67. (In Korean)

24. Choi, H.; Noh, H. Revitalization Measures of Local Tourism Based on its Characteristics: Focused on Suwon Hwaseong Cultural Festival. J. Assoc. Korean Photo-Geogr. 2009, 19, 27-35. (In Korean)

25. Hur, M.H.; Sa, Y.J.; Kim, W.S. Measurement of the Economic Benefits of Tourism Program for Suwon Hwaseong. J. KRSA 2009, 25, 23-46.

26. Lee, J.; Cho, S. A Study on the Plan of the Historical and Cultural Trail Network Utilizing Old Roads of Hwaseong Fortress, Suwon City. J. Korean Inst. Tradit. Landsc. 2011, 9, 97-112. (In Korean)

27. Kim, J. The Establishment of Suwon's Identity and the Urban Regeneration Based on World Heritage of Suwon Hwaseong. Local Hist. Local Cult. 2016, 19, 39-70. (In Korean) [CrossRef]

28. Hwang, H. Study on the Use of Region Branding of Historical Space: Focusing on the Suwon Hwaseong Temporary Palace Area. J. Korea Cult. Technol. 2011, 12, 139-161. (In Korean)

29. Ahn, Y.; Park, S. Development of Elements for Locally Specialized Performance Contents based on the World Heritage, Suwon Hwaseong Fortress. Korean J. Dance 2015, 73, 71-92. (In Korean)

30. Oh, S. The Investigation on Management Plan for the World Heritage 'Suwon Hwaseong Fortress' by Participant Observation. Int. J. Tour. Manag. Sci. 2013, 28, 237-257. (In Korean)

31. Lee, H.; Kwon, J. Context Adaptive Mobile Cultural Tourism Contents Service: Experiments at the Hwaseong Castle of Suwon. J. Korean Inst. Inf. Technol. 2010, 8, 191-202. (In Korean)

32. Nam, Y.; Um, S. Identifying potential markets to promote the mobile tourism application service at a tourist site. Int. J. Tour. Manag. Sci. 2014, 29, 237-255. (In Korean)

33. Choi, H. A Study on the Development Plan Using Evaluation of Local Cultural Festival: Focused on Suwon Hwaseong Cultural Festival. Glob. Cult. Contents 2018, 32, 279-298. (In Korean)

34. Kavaratzis, M.; Ashworth, G. City Branding: An Effective Assertion of Identity or a Transitory Marketing Trick? Tijdschr. Econ. Soc. Geogr. 2005, 96, 506-514. [CrossRef]

35. Kavaratzis, M. From city marketing to city branding: Towards a theoretical framework for developing city brands. Place Brand. 2004, 1, 58-73. [CrossRef]

36. Kavaratzis, M.; Braun, E.; Zenker, S. My City-My Brand: The Role of Residents in Place Branding. J. Place Manag. Dev. 2013, 6, 18-28. [CrossRef]

37. Cleave, E.; Arku, G.; Sadler, R.; Kyeremeh, E. Place Marketing, Place Branding, and Social Media: Perspectives of Municipal Practitioners. Growth Chang. 2017, 48, 1012-1033. [CrossRef]

38. Sevin, E. Branding Cities in the Age of Social Media Comparative Assessment of Local government performance. In Social Media and Local Governments: Theory and Practice; Sobaci, M., Ed.; Springer: Basel, Switzerand, 2016; ISBN 978-3-319-17721-2.

39. Kavaratzis, M.; Hatch, M. The Dynamics of Place Brands: An Identity-based Approach to Place Branding Theory. Mark. Theory 2013, 13, 69-86. [CrossRef]

40. Szondi, G. Branding Budapest. In City Branding: Theory and Cases; Dinnie, K., Ed.; Palgrave McMillan: New York, NY, USA, 2011; ISBN 978-0-230-24185-5.

41. Wardrop, K. Edinburgh: Scotland's Inspiring Capital. In City Branding: Theory and Cases; Dinnie, K., Ed.; Palgrave McMillan: New York, NY, USA, 2011; ISBN 978-0-230-24185-5.

42. Kim, Y.; Kim, P. Seoul City Branding: The Case of Seoul's International Brand Communication. In City Branding: Theory and Cases; Dinnie, K., Ed.; Palgrave McMillan: New York, NY, USA, 2011; ISBN 978-0-230-24185-5.

43. Björner, E. International Positioning through online City Branding: The Case of Chengdu. J. Place Manag. Dev. 2013, 6, 203-226. [CrossRef]

44. Sevin, E. Understanding Cities through City Brands: City Branding as a Social and Semantic Network. Cities 2014, 38, 47-56. [CrossRef]

45. Hansen, D.; Shneiderman, B.; Smith, M.A. Analysing Social Media Networks with NodeXL: Insights from a Connected World; Morgan Kaufmann: Burlington, MA, USA, 2011; ISBN 978-0-12-382229-1.

46. McPherson, E. Spot news versus reportage: Newspaper models, the distribution of newsroom credibility, and implications for democratic journalism in Mexico. Int. J. Commun. 2012, 6, 2301-2317. 
47. Node XL Korea. Catching Up NodeXL; Paradigm Book: Seoul, Korea, 2015; ISBN 979-11-955480-3-3. (In Korean)

48. Burt, R. Brokerage and Closure; Oxford University Press: Oxford, UK, 2005; ISBN 0191622850.

49. Burt, R. Structural Holes: The Social Structure of Competition; Harvard University Press: Cambridge, MA, USA, 1995; ISBN 0674843711.

50. Suwon City and·'2016 Visit Year Suwon Hwaseong' Promotion Bureau. 2016 Visit Year Suwon Hwaseong White Paper: Jeongjo, Pursuing His Dream in Suwon; 2016. Available online: https:/ / www.suwon.go.kr/commonupload/visitsuwon/2016visit_down.pdf (accessed on 26 May 2018). (In Korean)

51. Kang, Y. The Assessment of Visit Year 2016 Suwon Hwaseong; Suwon Research Institute: Suwon, Korea, 2017; Available online: https: / / www.suwon.re.kr/board/board.php?bo_table=research_reports\&wr_id=174 (accessed on 26 May 2018). (In Korean)

52. Gyeonggi Cultural Foundation. Available online: http://www.ggcf.kr/archives/71192 (accessed on 26 May 2018).

53. Suwon City Hall. Available online: http://www.suwon.go.kr/web/visitsuwon/pages/etc01/pages-05-03.do (accessed on 26 May 2018).

(C) 2018 by the authors. Licensee MDPI, Basel, Switzerland. This article is an open access article distributed under the terms and conditions of the Creative Commons Attribution (CC BY) license (http://creativecommons.org/licenses/by/4.0/). 